\title{
Changes in met perceived need for mental healthcare in Australia from 1997 to $2007^{\dagger}$
}

Graham N. Meadows and Irene Bobevski

\section{Background}

The Australian National Survey of Mental Health and Wellbeing conducted in 1997 and 2007 allows for exploration of changes in perceptions of mental healthcare. Major demographic, economic and health-behaviour changes have unfolded in Australia during this time. Governments also have increased spending on mental health services and been active in mental healthcare policy-making and implementation.

\begin{abstract}
Aims
To compare rates of meeting of perceived need for mental healthcare between these two surveys dealing with adjustable sources of error

\section{Method}

Combined data-sets from 1997 and 2007 were analysed to provide weighted population estimates. Selection, indirect standardisation to a common reference population and multinomial logistic regression were employed, addressing bias and confounding.
\end{abstract}

\section{Results}

Between 1997 and 2007 perceived need for information, counselling and skills training among people who consulted a general practitioner, psychiatrist, or psychologist for mental health reasons has increased. Within these service users, increases in perceived responses from services are evident among people who have perceived needs for information provision and counselling

\section{Conclusions}

Policy and service changes are among possible causal explanations. Generally, trends are in the direction that policy changes were intended to achieve, giving some encouragement that these initiatives have had some effect. Reduced unmet perceived need suggests improved access to some interventions. However, the proportion of service responses to perceived need seen as sufficient is generally unchanged. This suggests the adequacy of treatments offered, as perceived by the Australian public, may not have improved and that a continued focus on quality of care is important for the future.

\section{Declaration of interest}

None.
National epidemiological surveys of mental disorders conducted in 1997 and 2007 established the Australian National Survey of Mental Health and Wellbeing (NSMHWB) programme. Assessment of perceived needs for care and perceived sufficiency of service response to such perceived needs featured in both surveys. This mirrored a policy shift towards greater valuing of the patients' perspective in assessment and design of mental health services. ${ }^{1}$ Although expert assessment of need would yield important insights, perceived need assessment is more practicable in a large survey. The first-person perspective has also been argued to be an important complementary perspective in understanding patterns of service use. ${ }^{2}$ In this, survey methods can reflect realities of clinical care within which asking the patient their view of what might be helpful and monitoring their view of treatment offered is good practice. Self-ratings of symptoms have been seen to predict measures of quality of life above comparable clinician ratings, and changes in patient-rated unmet need have been shown to predict improvement in quality of life. ${ }^{3,4}$

The Perceived Need for Care Questionnaire (PNCQ) was rigorously developed to measure user appraisals of mental healthcare needs and service responses. ${ }^{5,6}$ Analyses from Australia have been reported by multiple research groups. ${ }^{7-10}$ The PNCQ has been adopted in other programmes internationally ${ }^{1-12}$ with translation into Cantonese, Dutch, French and Spanish. One important objective of better service provision would be decreased prevalence of symptomatic disorders but changes in instrumentation between the Composite International Diagnostic Interview (CIDI) v.2.1 used in $1997^{13}$ and v.3.0 used in $2007^{14}$ are such that these comparisons cannot be made with any confidence. Time anchors

'See editorial, pp. 443-444, this issue. for questions critical to diagnostic classifications differ between the instruments so that even if an attempt were to be made to construct common severity criteria such as has been done in other survey contexts, ${ }^{15}$ it is very doubtful that any valid comparisons could be made. The PNCQ stands in contrast to the muchchanged CIDI in that core PNCQ content from 1997 was purposively retained in 2007 for comparability. If careful attention is paid to case inclusion and coding, then the PNCQ as used in 1997 and 2007 can yield closely comparable results. An earlier PNCQ-based paper compared crude rates of met perceived need for 1997 and 2007. Overall estimates of population met perceived need were $5.7 \%$ in 1997 and $6.2 \%$ in 2007. Met perceived needs for information, medication, counselling and skills training all seemingly increasing by between 1 and $2 \%$ of the adult population. ${ }^{8}$ This might indicate substantial improvement in meeting of perceived needs through 1997 to $2007^{8}$ but limited access to the data at that time meant that key sources of bias could not be excluded. With the confidentialised unit record file from the 2007 survey more recently available to researchers, ${ }^{16}$ this paper extends examination of perceived need for care. These analyses go much further in controlling for sources of bias in assessing whether the profile of perceived needs has changed from 1997 to 2007.

Specifically then, in this study we aim to describe changes in patterns of perceived need for mental healthcare between 1997 and 2007 in Australia. We cannot expect to establish causation through such a descriptive study; nevertheless, specific hypotheses are that public awareness campaigns conducted between 1997 and 2007 will have led to more people in contact with services for mental healthcare having perceived needs for care in 2007 than in 1997, while the reforms designed to improve access and provision of care should mean these perceived needs will be more 
often responded to and more frequently met. In view of the evidence of improved mental health literacy and significant increase in the provision of psychological services during the 1997-2007 decade, it would be reasonable to conjecture that changes in perceived need and meeting of need would be most prominent in the areas of mental health information provision and psychological treatment.

\section{Method}

The 1997 and 2007 NSMHWB were conducted by the Australian Bureau of Statistics on a stratified multistage probability sample of the Australian population, including participants from all eight states and territories. The 1997 survey ${ }^{17}$ included people aged 18 to $75+$ with no upper limit on age. It had a sample size of 10641 and $78 \%$ response. The 2007 survey included people aged 16 to 85 years. Sample size was 8841 with a lower $60 \%$ response rate. The Australian Bureau of Statistics examined response bias in 2007 through comparisons with other national and international data sources and a non-response follow-up survey. This indicated that non-respondents may have had distress scores up to $10 \%$ higher, ${ }^{16}$ so possibly a marginally higher prevalence of mental disorders. Sensitivity analyses conducted by the Australian Bureau of Statistics suggested that the differential response bias seemed unlikely of itself to lead to statistically different findings between the two surveys. ${ }^{16}$ Details of survey conduct, administration, quality control, issues of response rates and weighting all have been described elsewhere. ${ }^{18}$

Both surveys included the following measures that we shall consider in this paper. For 12 months prior to interview selfreport of mental health services use was captured, then perceived needs and barriers to care as measured by the PNCQ. ${ }^{6}$ The PNCQ uses self-ratings to assess five areas of perceived need for mental healthcare:

(a) information (about mental illness, its treatment and available services);

(b) medication (medicine or tablets for mental health problems);

(c) counselling (psychotherapy, cognitive-behavioural therapy, counselling);

(d) social intervention (practical help to sort housing or money problems); and

(e) skills training (help to improve ability to work, care for oneself or home, or to use time in other ways).

Participants are categorised based on their responses as either being in perceived need or having no perceived need for mental healthcare in each of the above five areas. For those with perceived need, perceived needs are further categorised as either: fully met (if they received as much help as they perceived was needed); partially met (if they received help, but not as much as they perceived was needed); and unmet (if a perceived need existed, but no help was received).

The PNCQ as used in $2007^{8}$ was extended from the version used in 1997 but changes were made with attention to the importance of comparison of results from the two surveys. Mostly, changes were added as branch questions and so did not change the text of the stem questions as asked in 1997. Some items in perceived-need areas (d) and (e) above that were grouped in 1997 were asked separately in 2007 but content was common. Changes to CIDI affected the entry rules for the PNCQ between the surveys for people who did not use services, but in both surveys all users of any service for a mental health problem were asked the PNCQ questions. Hence, restricting analyses to a common set of service users removes CIDI changes as a source of selection bias in comparisons. For this paper we restrict consideration of PNCQ findings to people with service use in the previous year and to PNCQ content common between 1997 and 2007.

Service use was determined by asking people whether they consulted listed providers in the previous 12 months. There were changes in lists offered in 1997 and 2007, but questions for consulting general practitioners (GPs), psychiatrists and psychologists were identical. Therefore, analysis was restricted to people who consulted at least one of these three providers for mental health reasons in the previous 12 months. Most people who used mental health services in 1997 (84\%) and in 2007 (86\%) consulted at least one of a GP, a psychiatrist or a psychologist.

Differences between the two survey times in levels of psychological distress might confound findings in regard to perceived need and we will consider this. Psychological distress in the previous 4 weeks was assessed by the Kessler Psychological Distress Scale (K-10). ${ }^{19-21}$ The K-10 score is based on experience of ten emotional distress items in the previous 30 days rated on a Likert scale from 'not at all' to 'all the time'. The ten items were included in both the 1997 and 2007 surveys, although with some minor wording and item-ordering differences. Final scores range from 10 to 50, with higher scores indicating higher levels of distress. Score bands of different levels of distress have been established by Australian research ${ }^{19}$ (10-15 low; 16-21 medium, 22-29 high; and 30-50 very high).

\section{Analysis}

The Australian Bureau of Statistics confidentialised unit record files for 1997 and 2007 use similar weighting methodology. Each included sample weights derived both from design information and post-stratification weighting for calibration with population benchmarks, as well as a set of replicate weights for variance estimation using the jacknife replication technique. The jacknife replication method derives outputs from repeated analyses using the replicate weights so as to take account of design error in the calculation of statistics. ${ }^{16}$

The 1997 survey contained 30 replicate weights and the 2007 survey contained 60 replicate weights corresponding to each sample weight. The approach to working with combined data-sets was based on well-established and documented methodology used to compare cross-sectional health surveys with similar weighting techniques, such as the Health Information National Trends Survey (HINTS ${ }^{22}$ and the California Health Interview Survey. ${ }^{23}$ Ninety new replicate weights were created such that only the respective replicate weights for each survey contributed to the variance estimation for that survey.

To make the age range as comparable as possible between the two surveys and within constraints on available age-range coding within the released data-set, we restricted the analysis for this paper to people aged 20-69. Data were analysed using Stata 9.0 Intercooled for Windows XP.

The larger Australian population in 2007 also had a changed age-gender distribution that could make direct comparison of unstandardised rates misleading. In these analyses the 1997 survey population structure was indirectly standardised by age and gender to the 2007 population by using post-stratification weights based on the 2007 age-gender bands. Comparisons of rates are thereby corrected for these demographic shifts.

Within each perceived need category and associated level of perceived need, percentage frequencies and percentage differences 1997-2007 with confidence intervals were calculated, with statistical testing for differences in proportions. As a further 
investigation of the extent of changes in perceived need between 1997 and 2007, frequencies of perceived needs per person were also compared, using a chi-squared test.

Multinomial logistic regressions were carried out to investigate in more depth the relative changes of proportions of fully met $v$. unmet perceived need, partially met $v$. unmet perceived need, and fully met $v$. partially met perceived need for each perceived need category over time, controlling for age and gender. A separate multinomial regression was carried out for each perceived need category.

To establish whether levels of psychological distress have changed, people who had consulted either a GP, a psychiatrist or a psychologist for mental health reasons in the previous 12 months were compared on their K-10 score bands with a chi-squared test.

\section{Results}

The 1997-2007 percentage frequencies for each perceived need category are presented in Table 1, also differences and significance of differences in proportions. For 1997 and 2007, the most frequently endorsed perceived need is for counselling, followed by medication and information. Least-endorsed perceived needs are for skills training and social intervention.

Table 1 shows a consistent increase in perceived need across all categories from 1997 to 2007. The largest increases, which are statistically significant, occurred for information (18.3\%) followed by skills training $(9.6 \%)$ and counselling $(5.9 \%)$. There was a significant increase in the total number of perceived needs per person in 2007 compared with $1997 \quad\left(\chi_{(1, \mathrm{n}=1909)}^{2}=15.9\right.$, $P<0.01)$. In 2007 there were more people with a total of three to five perceived needs $(47.4 \%, 95 \%$ CI $42.2-52.7)$ compared with 1997 (34.1\%, 95\% CI 30.1-38.3). In 2007 there also were fewer people with zero to two perceived needs $(52.6 \%$, 95\% CI 47.3-57.8) compared with 1997 (65.9\%, 95\% CI 61.8-69.9).

Table 2 examines percentage frequencies and differences with associated confidence intervals and significance between 1997 and 2007 for fully met, partially met and unmet perceived need for each of the five categories. Table 2 shows that consistently across both survey years the larger proportion of perceived need for medication, counselling and information is mostly met in that rank-order. There are large proportions of unmet perceived need for skills training and particularly for social interventions. There is a significant decrease in overall unmet perceived need $(-4.1 \%)$, in unmet perceived need for information $(-12.2 \%)$ and counselling $(-7.4 \%)$ from 1997 to 2007. There are no significant changes in part met and fully met perceived need.

A separate multinomial regression was carried out for each perceived-need category with perceived-need category as the dependent variable, year of survey as the independent variable (using 1997 as the reference category) and gender and age as covariates (Table 3). These results indicate that for information and counselling, and for the overall perceived-needs category, in 2007 compared with 1997, people reported significantly higher proportions of fully met perceived need and partially met perceived need than unmet perceived need. There were no significant changes in proportions of fully met perceived need compared with partly met perceived need between 1997 and 2007.

It appears that people who expressed a perceived need for information or counselling were more likely to get at least some help for these perceived needs in 2007 than in 1997 (therefore less unmet perceived need). However, for the people who did obtain help for information or counselling, there is no significant change between 1997 and 2007 in the proportion of people receiving help of this kind who judged it sufficient for their perceived needs (that is 'met' $v$. 'part met' perceived need).

There were no significant changes in the meeting of perceived need for medication, social intervention and skills training between 1997 and 2007. However, there is a trend for a higher proportion of fully met perceived need compared with only partially met perceived need for social intervention, which almost reaches statistical significance.

In summary, the above results indicate that differences in increased perceived need and in improved service response from 1997 to 2007 are most evident in the areas of information provision and counselling. A possible confounder for these findings would be present if there were appreciable differences in levels of symptoms typically found among service users in the different surveys. To allow for consideration of this, among people who consulted any of a GP, a psychiatrist or a psychologist for mental health reasons, the percentage of respondents in each score band of the K-10 was calculated for 1997 and 2007. In 1997 the percentages of respondents within each K-10 score band were as follows: low 34.1\% (95\% CI 30.1-38.4); medium 31.9\% (95\% CI 28.6-35.3); high 21.5\% (95\% CI 18.0-25.5); and very high $12.5 \%$ (95\% CI 10.7-14.6). In 2007 these results were: low 29.9\% (95\% CI 24.4-36.1); medium 32.3\% (95\% CI 27.9-36.9); high $24.9 \%$ (95\% CI 21.1-29.2); and very high $12.9 \%$ (95\% CI 9.8-16.9). No significant differences were found in the K-10 score bands between 1997 and $2007\left(\chi_{(3, n=1909)}^{2}=0.81, P=0.48\right)$. This suggests that changes in distress levels are unlikely to be strong sources of confounding in these comparisons.

Although Australian Bureau of Statistics sensitivity analyses suggested generally that non-response would be an unlikely cause of such significant differences, ${ }^{16}$ we examined sensitivity of significant differences in unmet need among service users to a hypothetical scenario of changed response rates. To consider the possible effect that an increase in the 2007 response rate might have had, we simulated a $78 \%$ response rate in 2007 , as in 1997.

Table 1 Percentage frequencies, percentage differences and confidence intervals for the five perceived-need categories and for overall perceived need for the 1997 and the 2007 surveys, for people who consulted a general practitioner, a psychiatrist or a psychologist for mental health reasons

\begin{tabular}{|c|c|c|c|c|c|c|}
\hline & \multicolumn{2}{|c|}{$\begin{array}{c}1997 \text { (weighted } n=1173464 ; \\
\text { unweighted } n=1054 \text { ) }\end{array}$} & \multicolumn{2}{|c|}{$\begin{array}{c}2007 \text { (weighted } n=1478006 ; \\
\text { unweighted } n=855 \text { ) }\end{array}$} & \multicolumn{2}{|c|}{$\begin{array}{l}\text { Percentage differences } \\
\text { 2007-1997 }\end{array}$} \\
\hline & $\%$ & $(95 \% \mathrm{Cl})$ & $\%$ & $(95 \% \mathrm{Cl})$ & $\%$ & $(95 \% \mathrm{Cl})$ \\
\hline Any perceived need & 92.6 & (90.7 to 94.5$)$ & 95.9 & (91.5 to 100$)$ & 3.3 & (1.5 to 8.1$)$ \\
\hline Perceived need for information & 40.3 & (36.4 to 44.2$)$ & 58.6 & (53.6 to 63.5) & $18.3^{*}$ & (12.0 to 24.6$)$ \\
\hline Perceived need for medication & 63.6 & (59.8 to 67.4) & 68.9 & (62.9 to 74.9$)$ & 5.3 & $(-1.8$ to 12.4$)$ \\
\hline Perceived need for counselling & 67.5 & (64.8 to 70.3$)$ & 73.4 & (68.8 to 78.0$)$ & $5.9^{*}$ & (0.5 to 11.3$)$ \\
\hline Perceived need for social intervention & 13.0 & (10.4 to 15.6$)$ & 17.2 & (12.5 to 21.8$)$ & 4.2 & $(-1.2$ to 9.5$)$ \\
\hline Perceived need for skills training & 19.3 & (16.6 to 22.0$)$ & 28.9 & (23.7 to 34.1$)$ & $9.6^{*}$ & (3.7 to 15.5$)$ \\
\hline
\end{tabular}




\begin{tabular}{|c|c|c|c|c|c|c|}
\hline & \multicolumn{2}{|r|}{1997} & \multicolumn{2}{|c|}{2007} & \multicolumn{2}{|c|}{ Percentage differences 2007-1997 } \\
\hline & $\%$ & $(95 \% \mathrm{Cl})$ & $\%$ & $(95 \% \mathrm{Cl})$ & $\%$ & $(95 \% \mathrm{Cl})$ \\
\hline \multicolumn{7}{|c|}{ Any perceived need } \\
\hline Fully met & 54.2 & (50.6 to 57.8$)$ & 54.4 & (49.0 to 59.8$)$ & 0.2 & $(-6.3$ to 6.7$)$ \\
\hline Part met & 41.1 & (37.7 to 44.5$)$ & 44.9 & (39.6 to 50.3 ) & 3.8 & $(-2.5$ to 10.1$)$ \\
\hline Unmet & 4.7 & (3.1 to 6.3) & 0.6 & $(0.0$ to 1.2$)$ & $-4.1^{*}$ & $(-5.8$ to -2.3$)$ \\
\hline \multicolumn{7}{|c|}{ Perceived need for information } \\
\hline Fully met & 54.1 & (48.6 to 59.6$)$ & 60.6 & (54.3 to 67.0$)$ & 6.6 & $(-1.9$ to 15.0$)$ \\
\hline Part met & 15.7 & (12.2 to 19.2$)$ & 21.4 & (16.1 to 26.6$)$ & 5.7 & $(-0.6$ to 12.0$)$ \\
\hline Unmet & 30.2 & (25.5 to 35.0$)$ & 18.0 & (12.7 to 23.3 ) & $-12.2^{*}$ & $(-19.3$ to -5.1$)$ \\
\hline \multicolumn{7}{|c|}{ Perceived need for medication } \\
\hline Fully met & 87.0 & (84.2 to 89.8$)$ & 88.1 & (84.8 to 91.5$)$ & 1.2 & $(-3.2$ to 5.5$)$ \\
\hline Part met & 9.0 & (6.6 to 11.4$)$ & 9.2 & (6.1 to 12.3 ) & 0.2 & $(-3.7$ to 4.1$)$ \\
\hline Unmet & 4.0 & (2.0 to 6.0$)$ & 2.6 & (1.1 to 4.1$)$ & -1.4 & $(-3.9$ to 1.1$)$ \\
\hline \multicolumn{7}{|c|}{ Perceived need for counselling } \\
\hline Fully met & 63.2 & (58.4 to 67.9 ) & 69.9 & (65.0 to 74.9$)$ & 6.8 & $(-0.1$ to 13.6$)$ \\
\hline Part met & 16.9 & (14.3 to 19.6$)$ & 17.5 & (12.9 to 22.2 ) & 0.6 & $(-4.7$ to 6.0$)$ \\
\hline Unmet & 19.9 & (16.1 to 23.8 ) & 12.5 & (9.5 to 15.5$)$ & $-7.4^{\star}$ & $(-12.3$ to -2.5$)$ \\
\hline \multicolumn{7}{|c|}{ Perceived need for social intervention } \\
\hline Fully met & 22.5 & (14.6 to 30.3$)$ & 35.4 & (22.6 to 48.1 ) & 12.9 & $(-2.1$ to 27.8$)$ \\
\hline Part met & 7.8 & (3.2 to 12.4 ) & 3.8 & $(0.9$ to 6.7$)$ & -4.0 & $(-9.5$ to 1.5$)$ \\
\hline Unmet & 69.8 & (61.5 to 78.0$)$ & 60.9 & (48.1 to 73.6$)$ & -8.9 & $(-24.0$ to 6.3$)$ \\
\hline \multicolumn{7}{|c|}{ Perceived need for skills training } \\
\hline Fully met & 45.9 & (40.1 to 51.8 ) & 48.7 & (38.7 to 58.7 ) & 2.8 & ( -8.8 to 14.4 ) \\
\hline Part met & 13.5 & (8.5 to 18.5 ) & 14.9 & (7.1 to 22.7 ) & 1.4 & ( -7.8 to 10.6$)$ \\
\hline Unmet & 40.6 & (34.3 to 46.9 ) & 36.4 & (26.7 to 46.1 ) & -4.2 & $(-15.8$ to 7.5$)$ \\
\hline
\end{tabular}

To do this we added statistics from a notional extra $18 \%$ of respondents to the 2007 survey. We assumed the same rate of service use among simulated new responders but with unmet need among service users scaled up by first, a factor of 1.2, then more extreme values of 1.5 and 2 . Unweighted relative risk ratios and confidence intervals ${ }^{24}$ were calculated for proportions of unmet need in 1997 v. 2007 among service users for any need, information and counselling. Relative risk ratios remained significant for any unmet need under all three scenarios and for counselling for the first scenario. The finding for perceived need for information was more sensitive and significance at $P<0.05$ was not maintained in these alternative scenarios.

\section{Discussion}

\section{Changes in Australia between 1997 and 2007}

Our findings need to be considered within the context of changes in health services as well as social, demographic and economic changes between 1997 and 2007. By the time of the 1997 NSMHWB, the transition from institutional to community-based care was well under way in Australia. Changes continued through the further decade: annual expenditure on mental healthcare nationally increased from $\$ 164$ million dollars to $\$ 251$ million; ${ }^{25}$ new psychotropics appeared, with novel antidepressants becoming widely used. There were major structural changes in primary and specialist mental healthcare, with promotion of training for primary care staff and efforts to change public attitudes. ${ }^{26}$ National survey work confirmed that recognition by members of the public of a vignette depicting someone with a depressive disorder doubled from 1996 to $2003^{27}$ to over $60 \%$. This change varied in degree across the eight states and territories but positive change was present and substantial across the whole country. ${ }^{27}$
Table 3 Multinomial logistic regressions with perceived-

need category as the dependent variable, year of survey as the independent variable (using 1997 as the reference

category) and controlling for gender and age for people who consulted either a general practitioner, a psychiatrist or

a psychologist for mental health reasons and reported a perceived need in the respective category

Perceived-need comparisons (2007 v. 1997)

Relative rate ratio $(95 \% \mathrm{Cl}) \quad P$

\begin{tabular}{llll} 
Any perceived need & & & \\
Fully met $v$. unmet & $7.2^{*}$ & $(2.3-22.2)$ & 0.001 \\
Part met $v$. unmet & $8.1^{*}$ & $(2.7-24.6)$ & 0.000 \\
Fully met $v$. part met & 0.9 & $(0.7-1.2)$ & 0.352 \\
\hline Perceived need for information & & & \\
$\quad$ Fully met $v$. unmet & $1.9^{*}$ & $(1.2-2.9)$ & 0.005 \\
Part met $v$. unmet & $2.4^{*}$ & $(1.4-4.0)$ & 0.001 \\
Fully met $v$. part met & 0.8 & $(0.5-1.2)$ & 0.285 \\
\hline Perceived need for medication & & & \\
Fully met $v$. unmet & 1.5 & $(0.7-3.4)$ & 0.331 \\
Part met $v$. unmet & 1.5 & $(0.6-4.0)$ & 0.398 \\
Fully met $v$. part met & 1.0 & $(0.6-1.6)$ & 0.965 \\
\hline Perceived need for counselling & & & \\
Fully met $v$. unmet & $1.7 *$ & $(1.2-2.5)$ & 0.006 \\
Part met $v$. unmet & $1.7 *$ & $(1.1-2.7)$ & 0.027 \\
Fully met $v$. part met & 1.0 & $(0.7-1.5)$ & 0.967 \\
\hline Perceived need for social intervention & & & \\
Fully met $v$. unmet & 1.8 & $(0.9-3.7)$ & 0.105 \\
Part met $v$. unmet & 0.5 & $(0.2-1.6)$ & 0.266 \\
Fully met $v$. part met & 3.4 & $(1.0-11.8)$ & 0.052 \\
\hline Perceived need for skills training & & & \\
Fully met $v$. unmet & 1.2 & $(0.7-2.0)$ & 0.532 \\
Part met $v$. unmet & 1.2 & $(0.5-2.8)$ & 0.736 \\
Fully met $v$. part met & 1.0 & $(0.5-2.3)$ & 0.962 \\
* Significant values at the $\alpha=0.05$ level. & & & \\
\hline
\end{tabular}


New government funding for psychologists provided for 6 to 12 sessions of psychological treatment following a GP referral in a scheme that has had very positive systematic evaluation. ${ }^{28-30}$ Other changes in Australia during 1997-2007 should be noted: the Australian population increased from 18.3 to 20.8 million; the average age of the population increased from 35.9 to 37.8 years. ${ }^{31}$ Unemployment declined from a population rate of 8.3 to $4.3 \%{ }^{32}$ Gross domestic product increased from AUD \$145 billion in 1997 to AUD \$286 billion in 2007. ${ }^{33}$ The proportion of working age adults with a bachelors degree or above increased from $15.6 \%$ of the population to $24.1 \%$. Population smoking rates declined from 26 to $19 \%,{ }^{34}$ whereas recent work suggests that as Australian wines have become typically stronger, alcohol consumption in this period has appreciably increased. ${ }^{35}$ The surveys in 1997 and 2007 therefore provide an opportunity to examine changed experience of care in the population going along with these changes.

\section{Main findings}

Between 1997 and 2007, among Australians who consulted a GP, a psychiatrist, or a psychologist for their mental healthcare, we have found a significant increase in perceived need for information, counselling and skills training. There was also a significant apparent increase over this time period in the total number of perceived needs per person. There has been a decrease in unmet perceived need relative to fully met and partially met perceived need for information and counselling, as well as overall, among the above service users. Hence, a higher proportion of service users who perceive a need for information and counselling got at least some perceived response to these particular perceived needs in 2007 than in 1997. However, there were no significant changes in the proportions of fully met perceived need relative to partially met perceived need, suggesting that once help was received for a particular need there was no clear evidence here of changes in consumers' perceptions of whether the amount of help received was sufficient. Central estimates suggest this latter finding is not likely to be attributable to type II error.

Considering limitations of this study, despite all efforts by the Australian Bureau of Statistics to achieve a representative sample, differences in response rates were present and so varying selection bias could account for some of these apparent effects. It is possible, although not established, that prevalence of depression in some groups in Australia may have increased, and that could affect the overall need profile. ${ }^{36,37}$ The sections of the questionnaires considered here were set in interviews of different length and content, and thus the possibility of order effects from the surrounding interview cannot be excluded. There was some disaggregation of stem items in the 2007 PNCQ regarding social intervention and skills training ${ }^{8}$ that could have increased levels of perceived need endorsement here, although this finding was also present in the other items that were identical between the two surveys.

Although acknowledging these limitations, we have in these analyses paid careful attention to issues of comparability of instrumentation bias and possible population confounders. Sensitivity analyses suggest that key findings are robust to a reasonable range of likely response bias. We suggest that a balanced view of the findings is that among users of services from the providers examined, there has been a change in the perceptions of need and of how well it is being met, at least in the two domains broadly of talking therapies and of provision of information. These changes are in the direction of the a priori hypotheses we set out to examine and can be seen as aligned with the hoped-for outcomes from changes in Australia that have targeted service provision and public education. The changes in mental health literacy that are known to have occurred may have contributed to more needs being identified ${ }^{27}$ and the changes in service delivery nationwide could have contributed to greater service response once need was perceived. ${ }^{26}$ Nonetheless, the design of this work is such that causation cannot be established. Other influences on well-being and optimism about life or about the effectiveness of services might have had causal roles; when we compare the Australian public of 2007 with that of 1997 we find a public that is more affluent, often better educated and informed, with substantially changed patterns of substance use. Each of these changes and more could have played a part in generating these findings.

Large proportions of unmet perceived need remained over time for social intervention and skills training. In regard to these two perceived needs, it is important to point out that the analyses were constrained for the purposes of ensuring comparability to people who had consulted a GP, a psychiatrist or a psychologist. None of these three types of provider is specifically trained in the areas of social intervention and skills training, which are usually the domains of other professionals, such as social workers and occupational therapists.

In population survey work from the UK, between 1993 and 2000 increased use of medication was evident but not increased psychological treatments. ${ }^{38}$ In the present study medication provision also trended towards increase, although not significantly. The PNCQ typically rates medication needs as mostly met, ${ }^{7,8}$ and this likely reflects the difficulty that patients as consumers may have in identifying whether prescribed therapy is adequate to their needs. A patient as consumer may be more able to reach a judgement as to whether a psychological treatment has been provided adequately or not, even though this judgement will not necessarily correspond with adherence to evidence-based practice. Had the time period observed in this British work been applicable to the Australian National Survey programme, then we might have seen very different results. In Australia there was a major surge of antidepressant prescribing in the early and mid-1990s, which then flattened in the early 2000s. ${ }^{39}$ In contrast, the developments in psychological therapies provided in general practice in Australia have been much more a phenomenon of the first decade of the 21st century.

\section{Implications}

These findings should be considered for their implications for policy in Australia. If the findings of this work had been contrary to the directional hypotheses we began with, then this would certainly have been discouraging for policy-makers in Australia. More hopefully, we have found some changes in the anticipated directions. The range of other changes in the country that cannot be controlled for means that the findings cannot firmly be ascribed to government policy. They, however, provide some encouragement that mental health policy-making along with other social changes, is contributing to a positive shift in the engagement of consumers and providers in a number of forms of mental healthcare. Of some concern, the findings do not provide confirmation that once treatment is accessed it is any more likely to be perceived as sufficient. Although the capacity of the system to make some response to perceived needs from consumers may indeed have increased, this evidence supports the continuing need to strive towards improvements in the quality of this response.

\section{Funding}

This work was conducted within the resources of the Southern Health Adult Psychiatry Research, Training and Evaluation Centre (Southern Synergy), which receives significant financial support from Southern Health. 


\section{Acknowledgements}

We thank all the participants in the reported surveys. We acknowledge the Australian Government Department of Health and Aging and the Australian Bureau of Statistics for their essential roles in support and conduct of both the National Survey of Mental Health and Wellbeing 2007 and 1997

Graham N. Meadows, MD, FRANZCP, MRCPsych, MRCP(UK), Irene Bobevski, DPsych(Clin), Southern Synergy, School of Psychiatry and Psychology, Monash University, Victoria, Australia

Correspondence: Graham N. Meadows, Southern Synergy, c/o Wellington Road, Clayton, Victoria 3800, Australia. Email: graham.meadows@monash.edu

First received 7 Oct 2010, final revision 16 Jun 2011, accepted 28 Jul 2011

\section{References}

1 Australian Health Ministers. National Mental Health Policy. Mental Health Branch, Commonwealth Department of Health and Family Services, 1992.

2 Whiteford H, Groves A. Policy implications of the 2007 National Survey of Mental Health and Wellbeing. Aust N Z J Psychiatry 2009; 43: 644-51.

3 Lasalvia A, Ruggeri M, Santolini N. Subjective quality of life: its relationship with clinician-rated and patient-rated psychopathology. The South-Verona Outcome Project 6. Psychother Psychosom 2002; 71: 275-84.

4 Slade $\mathrm{M}$, Leese $\mathrm{M}$, Cahill $\mathrm{S}$, Thornicroft G, Kuipers E. Patient-rated mental health needs and quality of life improvement. Br J Psychiatry 2005; 187: 256-61.

5 Meadows G, Fossey E, Harvey C, Burgess P. The assessment of perceived need. In Unmet Need in Psychiatry (eds G Andrews \& S Henderson): 390-8. Cambridge University Press, 2000

6 Meadows G, Harvey C, Fossey E, Burgess P. Assessing perceived need for mental health care in a community survey: development of the Perceived Need for Care Questionnaire. Soc Psychiatry Psychiatr Epidemiology 2000; 35: 427-35.

7 Meadows G, Burgess P, Fossey E, Harvey C. Perceived need for mental health care, findings from the Australian National Survey of Mental Health and Wellbeing. Psychol Med 2000; 30: 645-56.

8 Meadows G, Burgess P. Perceived need for mental health care - findings from the 2007 Australian Survey of Mental Health and Wellbeing. Aust N Z J Psychiatry 2009; 43: 624-34.

9 Issakidis C, Andrews G. Service utilisation for anxiety in an Australian community sample. Soc Psychiatry Psychiatr Epidemiol 2002; 37: 153-63.

10 Parslow RA, Jorm AF. Predictors of partially met or unmet need reported by consumers of mental health services: an analysis of data from the Australian National Survey of Mental Health and Wellbeing. Aust N Z J Psychiatry 2001; 35: 455-63.

11 Sareen J, Cox BJ, Stein MB, Belik S, Meadows G, Asmundson GJ. Combat and Peacekeeping operations in relation to prevalence of mental disorders and perceived need for mental health care. Arch Gen Psychiatry 2007; 64: 1-10.

12 Penninx BW, Smit JH, Zitman FG, Nolen W, Beekman AT, van Dyck R. Netherlands study of depression and anxiety (NESDA): examining the longterm course of affective disorders. Eur Psychiatry 2007; 22 (suppl 1): S330.

13 Andrews G, Peters L. The psychometric properties of the Composite International Diagnostic Interview. Soc Psychiatry Psychiatr Epidemiol 1998; 33: $80-8$.

14 Kessler RC, Ustun B. The World Mental Health (WMH) survey initiative version of the World Health Organization (WHO) Composite International Diagnostic Interview (CIDI). Int J Methods Psychiatr Res 2004; 13: 93-121.

15 Kessler RC, Demler O, Frank RG, Olfson M, Pincus HA, Walters EE, et al. Prevalence and treatment of mental disorders, 1990 to 2003. N Eng/ J Med 2005; 352: 2515-23.

16 Australian Bureau of Statistics. National Survey of Mental Health and Wellbeing: Users Guide. Australian Bureau of Statistics, 2009.

17 Whiteford $\mathrm{H}$. Introduction: the Australian mental health survey. Aust $\mathrm{N} Z \mathrm{~J}$ Psychiatry 2000; 34: 193-6.
18 Slade T, Johnston A, Oakley-Browne M, Andrews G, Whiteford H. 2007 National Survey of Mental Health and Wellbeing: Description of methods and summary of key findings. Aust N Z J Psychiatry 2009; 43: 594-605.

19 Andrews G, Slade T. Interpreting scores on the Kessler Psychological Distress Scale (K10). Aust N Z J Public Health 2001; 25: 494-7.

20 Furukawa TA, Kessler RC, Slade T, Andrews G. The performance of the K6 and $\mathrm{K} 10$ screening scales for psychological distress in the Australian National Survey of Mental Health and Well-Being. Psychol Med 2003; 33: 357-62.

21 Kessler RC, Andrews G, Colpe L, Hiripi E, Mroczek DK, Normand SL, et al. Short screening scales to monitor population prevalences and trends in non-specific psychological distress. Psychol Med 2002; 32: 959-76.

22 Rizzo L, Moser RP, Waldron W, Wang Z, Davis WW. Analytic Methods to Examine Changes Across Years using HINTS 2003 \& 2005 Data. US Department of Health and Human Services, National Institutes of Health 2008 (http://hints.cancer.gov/docs/HINTS_Data_Users_Handbook-2008.pdf).

23 Lee S, Davis WW, Nguyen HA, McNeel TS, Brick JM, Flores-Cervantes I. California Health Interview Survey (CHIS) Methodology Paper: Examining Trends and Averages using Combined Cross-Sectional Survey Data from Multiple Years. California Health Interview Survey, 2007 (www.chis.ucla.edu/ pdf/paper_trends_averages.pdf)

24 Morris JA, Gardner MJ. Epidemiological Studies. In Statistics with Confidence (eds DG Altman, D Machin, TN Bryant, MJ Gardner). BMJ Books, 2000.

25 Department of Health and Ageing. National Mental Health Report 2010: Summary of 15 Years of Reform in Australia's Mental Health Services under the National Mental Health Strategy 1993-2008. Mental Health Reform Branch, Mental Health and Chronic Disease Division, Department of Health and Ageing, 2010

26 Australian Government Department of Health and Ageing. National Mental Health Report 2007: Summary of Twelve Years of Reform in Australia's Mental Health Services under the National Mental Health Strategy 1993-2005. Australian Government, 2007.

27 Jorm AF, Christensen H, Griffiths KM. Changes in depression awareness and attitudes in Australia: the impact of beyondblue: the national depression initiative. Aust N Z J Psychiatry 2006; 40: 42-6.

28 Australian Psychological Society. 'Better access' to Medicare Mental Health Items and Psychology Providers. Australian Psychological Society, 2007.

29 Council of Australian Governments. National Action Plan on Mental Health 2006-2011. Australian Government, 2006 (http://www.coag.gov.au/ coag_meeting_outcomes/2006-07-14/docs/nap_mental_health.pdf).

30 Pirkis J, Harris M, Hall W, Ftanou M. Evaluation of the Better Access to Psychiatrists, Psychologists and General Practitioners through the Medicare Benefits Schedule Initiative: Final Report. Centre for Health Policy, Programs and Economics, University of Melbourne, 2011.

31 Australian Bureau of Statistics. Australian Demographic Statistics, Jun 2010. Australian Bureau of Statistics, 2010 (http://www abs gov au/AUSSTATS/ abs@.nsf/DetailsPage/3101.0Jun\%202010).

32 Australian Bureau of Statistics. Labour Force, Australia, Jan 2011. Canberra, 2011 (http://www.abs.gov.au/ausstats/abs@.nsf/mf/6202.0).

33 Australian Bureau of Statistics. Australian National Accounts: National Income, Expenditure and Product, Dec 2010. Australian Bureau of Statistics, 2010 (http://www.abs.gov.au/ausstats/abs@.nsf/mf/5206.0).

34 Quit Victoria and VicHealth. Smoking Rates, Diseases, Secondhand Smoke and Costs. Quit Victoria, 2009.

35 Chikritzhs TN, Allsop SJ, Moodie AR, Hall WD. Per capita alcohol consumption in Australia: will the real trend please step forward? Med J Aust 2010; 193 . 594-7.

36 Jorm AF, Butterworth P. Changes in psychological distress in Australia over an 8-year period: evidence for worsening in young men. Aust $N \mathrm{Z} J$ Psychiatry 2006; 40: 47-50

37 Hawthorne G, Goldney R, Taylor AW. Changes in the prevalence of major depression in an Australian community sample between 1998 and 2008. Aust N Z J Psychiatry 2010; 44: 901-10.

38 Brugha TS, Bebbington PE, Singleton N, Melzer D, Jenkins R, Lewis G, et al Trends in service use and treatment for mental disorders in adults throughout Great Britain. Br J Psychiatry 2004; 185: 378-84.

39 Mant A, Rendle VA, Hall WD, Mitchell PB, Montgomery WS, McManus PR, et al. Making new choices about antidepressants in Australia: the long view 1975-2002. Med J Aust 2004; 181: S21-4. 